\title{
Chapter 3 \\ Agglomeration, Institution, and Social \\ Capital: Main Concepts and Methodologies
}

\begin{abstract}
The concepts and methodologies used to develop the survey questionnaires are discussed here. The dualism and inequality are not merely the results of policies but also the consequence of agglomeration forces and the interplay of policies and prevailing institution. On the other hand, potential benefits of the same forces could provide incentives for MSMEs to operate in clusters for collective action, the effectiveness of which depends crucially on the interplay of policies and social capital.
\end{abstract}

Keywords Interregional multipliers $\cdot$ Local capture $\cdot$ Cooperation $\cdot$ Cluster $\cdot$ Collective action
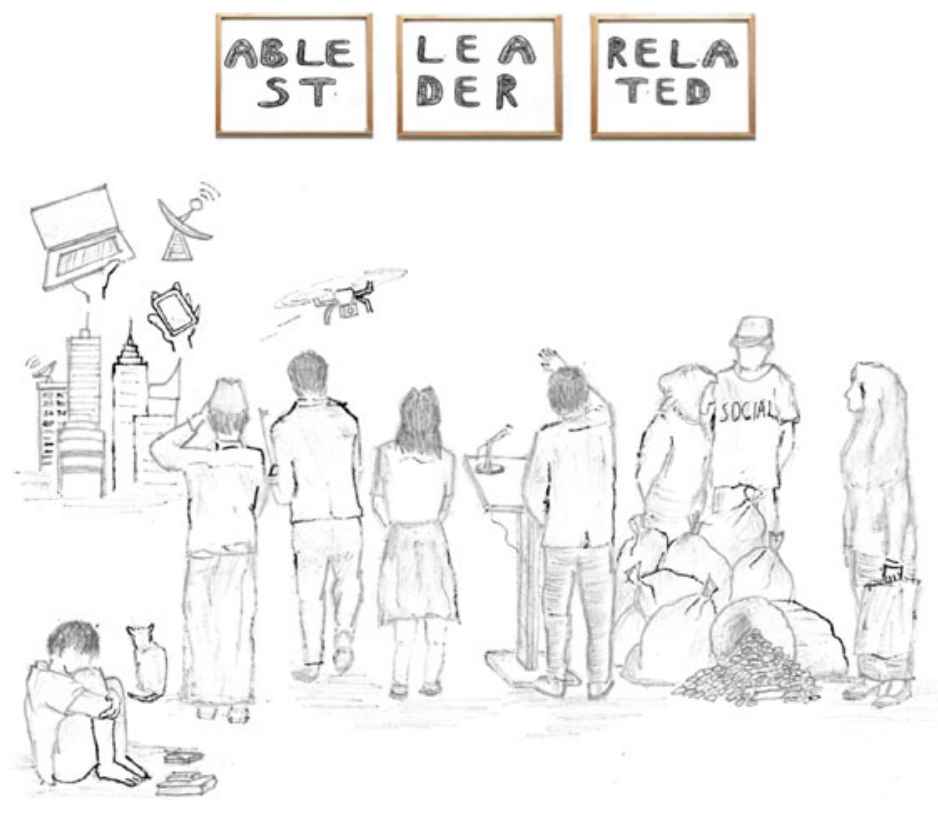


\section{Conversation}

A: "Dualism decreases when ABLEST firms and regions generate technological spillovers."

B: "Without incentives and resource mobility, no such spillovers will occur. As a result, the STABLE outcome would be a catastrophic agglomeration."

A: "To avoid that, and to improve the overall welfare, direct and open elections of local LEADERS during decentralization will help because local people know best about local conditions."

B: "But with widespread local capture and money politics, numerous REDEALS made by elected officials tend to worsen the overall welfare."

A: "In that case, we need to redouble the existing programs and policies RELATED to small businesses and periphery regions."

B: "The approach of relying on policies alone needs to be ALTERED. We need to use a set of design principles in formulating programs that capture the interplay of policy, institution, and social capital."

\section{Duality from Different Lenses}

An upshot of the analysis throughout the book is that, dualism and inequality in a large and diverse country like Indonesia are not merely the results of policies but also the consequence of agglomeration forces and the interplay between policies and the prevailing institution, in which social capital is an important part of. The concepts and methodologies based on relevant theories presented in this chapter provide a back up to such a conjecture. After discussing the process of agglomeration and external economies, the role of institution in shaping the duality in regional performance is explicated by using the institutional model of decentralization (IMD). The last part of the chapter presents a framework and the mechanisms how policies, institution and social capital work to affect the MSME performance. Before taking up those tasks, let us first interpret the observed inequality discussed in the preceding chapter from various lenses.

From the Game Theory perspective, inequality is an equilibrium solution similar to that in a 'prisoners dilemma' case, which is the most well-known social dilemma in which rational individuals in pursuit of their optimal outcome may end up not cooperating, resulting in a negative outcome, i.e., greater dualism. Think of MSMEs that need external assistance but for some reasons are neither willing nor able to utilize it even after considering the short and long term impact of it. ${ }^{1}$ As demonstrated in Beckenkamp (2006), prisoner's dilemma can become social dilemma even without

\footnotetext{
${ }^{1}$ Social dilemma refers to a setting in which individuals choose actions in an interdependent situation. When at least one outcome yields higher returns for all participants but participants making independent choices are not predicted to achieve such an outcome, individuals will take actions that generate lower joint outcomes than could have been achieved although these actions maximize
} 
a conflict between short-and long-term decisions. In Game Theory, social dilemmas are multi-persons decision-making problems in which individual interests are at odds with collective interests (Colman, 1995; Poppitz, 2011). In some cases, however, when individuals are given the capacity to recognize trustworthiness in others and able to withdraw from the program, the possibility of cooperation increases over time and it can reach relatively high levels when the number of participants also increases (Janssen, 2008).

From the Mechanism Design theory (Hurwicz, 1973), inequality is an outcome based on equilibrium decision that is best according to the information/messages that social planners use. In this case, the mechanism specifies the set of those messages. Once such a mechanism is in place, social planners "play a game" where they send the messages (e.g., providing low interest credit, lowering tax, introducing digital technology to MSMEs) as a function of their information. Hence, unlike the conventional assumption that policy makers "know everything," here conditional to a set of received messages (the 'mechanism') any transmitted information and decision that leads to dualism is optimal. The main task is to find that mechanism. In the context of dualism, that task translates into modeling social institutions that will produce an equilibrium decision compatible with the individual's or society's incentives that maximize social welfare.

Viewed from the perspective of Institutional Economics (North, 1990), observed inequality can be the results of interactions between the 'right' kind of policies and the 'wrong' kind of formal and informal institutions. While according to the standard economic theory a particular policy will produce an equilibrium outcome with minimum dualism, the implicit assumptions about enabling institutional arrangements may not hold. This is likely to occur when the assumed institutional arrangements are not compatible with the prevailing formal institution (e.g., rules, regulations) and informal institution (traditions, habits, enforcement). In the case of dualism, the prevailing institution may work to meet certain goals (say, higher growth and macro stability) but fail to avert a growing inequality or to make any compensating policies work effectively. While most literature on institution use property right as an example, as it can improve business environment, in cases when power asymmetry is strong to protect such a property right can worsen dualism (work only for the rich and the powerful).

Dualism and inequality can also be viewed from the perspectives of sociology, particularly in relation to the role of social capital in conferring information, influence, control, and sense of solidarity. Different people define social capital differently. Generally speaking, social capital is referred to as features of social organization, such as trust, networks, and norms, that facilitate coordination and cooperation for mutual benefit (Six et al., 2015). While the relation between social capital and inequality is complex, a major and most relevant dimension of inequality concerns the access to social capital, e.g., direct and indirect access to resources and network. Social capital can add long-term value by providing opportunities or network to increase

short-term material benefits to self (similar to a game where the Nash equilibrium for a single iteration of the game yields less than the socially optimal outcome). 
individuals' human capital (health, education, prestige), improve the ability of lessdeveloped regions to innovate and attract businesses, or increase MSMEs' capacity to enhance productivity and competitiveness. In many less-developed regions with limited resources and human capital, a lack of access to networks and linkages as part of social capital worsens the dualism. Insofar the survey in our study puts the emphasis on the role of social capital and its interaction with policy, the concept and components of social capital are discussed in greater details in the next chapter.

It is from the lens of regional economics that dualism and inequality are explained through the forces of agglomeration, a subject we discuss next.

\section{Agglomeration and External Economies}

As part of external economies of scale, agglomeration economies are closely associated with market structure. In addressing external economies to formulate heterodox challenges to standard economic doctrine, economists often use a multiple equilibria concept (Krugman, 1987; Murphy, Shleifer, \& Vishny, 1989; Romer, 1986). One of the contentious questions is, which equilibrium actually gets established? Unlike Marshall (1920) who contended that the outcome depends on the initial conditions (thus history), as well as tastes, technology, and factor endowments, Krugman (1991b) argued that expectations also matter, and both are in turn determined by the underlying structure of the economy. A long-established theory suggests that monopolistic competition in, say, intermediate goods, may lead to de facto external economies in the production of final goods (Graham, 1927). In a smaller configuration area (e.g., province versus nation, district vs province, etc.) with a smaller number of producers, market structure tends to be of the imperfect competition type along with increasing-returns-to-scale. Such a structure generates agglomeration forces that shape a country's spatial configuration. More specifically, they induce a concentration of activities in certain locations (Azis, 2020a; Fujita \& Thisse, 2002; Krugman, 1991a). A similar line of argument is applicable when one tries to explain the emergence of cities and urban centers.

In a dynamic context, the presence of technology spillovers and innovation in developed regions (DR) could reinforce the agglomeration forces. The endogenous growth theory popularized by Romer $(1986,1990,1994)$ emphasizes the role of monopolistic competition, externalities, and increasing returns to scale to explain why research \& development (R\&D) activities and innovation tend to persist in DR. Under imperfect competition, the incentive to spend on R\&D in DR does not fall, while new technologies brought by new entrants and the presence of knowledge spillovers reduce the $R \& D$ costs. As a result, new ideas generate economic rents that attract capital accumulation, and this causes market to expand with higher profit, attracting more labor pools to cause market to expand further (cumulative causation). As more activities tend to locate in DR, a scenario of extreme inequality arises.

Take the case of infrastructure development. Increased capital accumulation due to lower transport costs and trade costs can be further boosted by the technology 

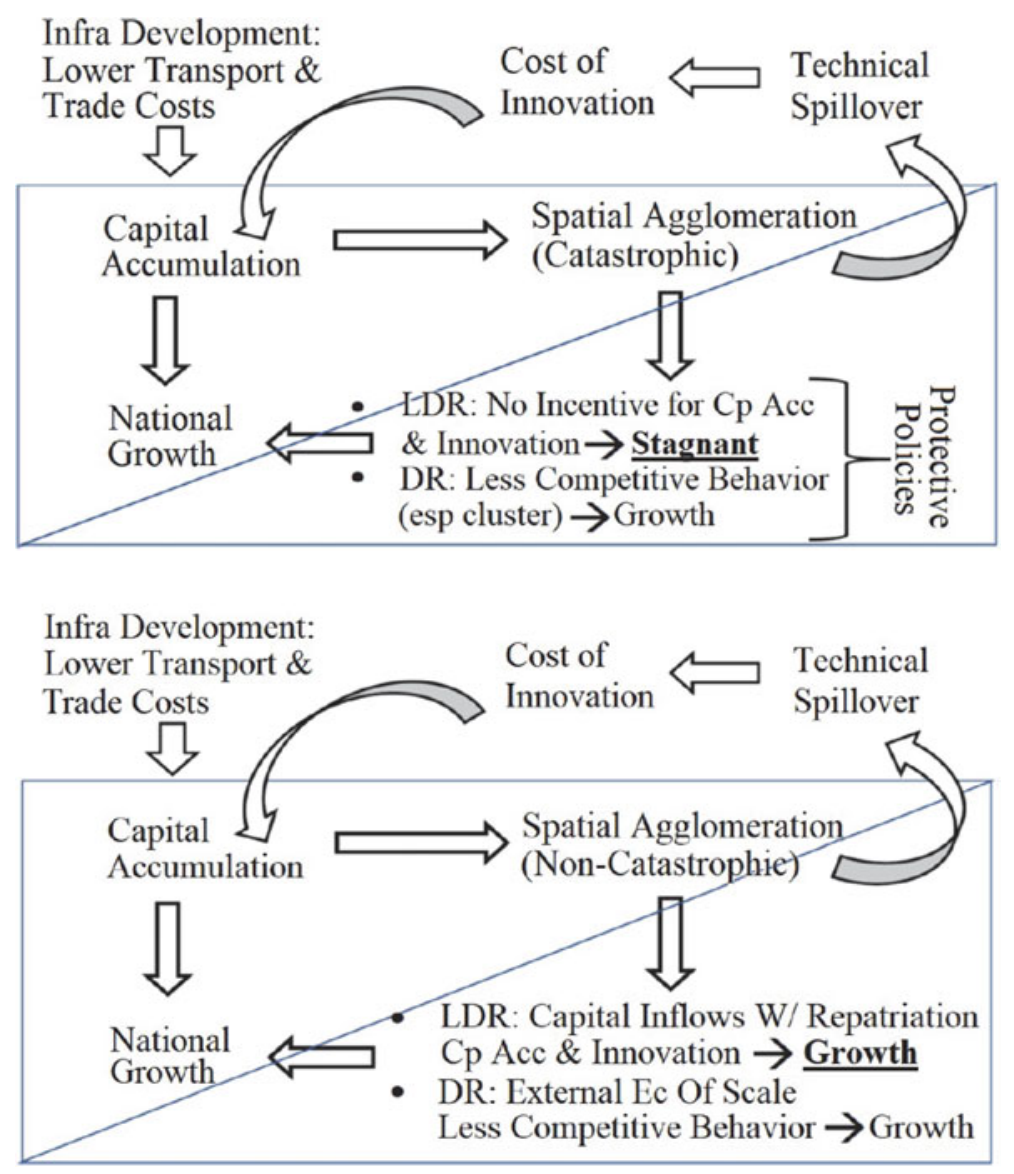

Fig. 3.1 Catastrophic and Non-Catastrophic Agglomeration. Source Azis (2020a)

spillover in DR that will reduce innovation costs. Such a spillover is reinforced by the agglomeration forces where activities continue to gain some external economies. As the process continues and becomes cumulative, DR capacity to boost national growth is strengthened. On the other hand, LDR remains stagnant if the interregional multipliers from DR to LR are not strong enough to counter the attractiveness of DR to pull more activities in. Hence, growth in DR accelerates while LDR economy remains stagnant. If capital and labor move from LR to DR, or resources in LR are exploited for activities in DR to process for export market, inequality between DR and LDR becomes worse. The mechanism of this 'catastrophic agglomeration' scenario is shown in the upper part of Fig. 3.1. To mitigate the effects, some protective policies are called for. ${ }^{2}$

\footnotetext{
2 The terms 'catastrophic agglomeration' was first used by Baldwin et.al (2004), the property of which is called the 'super-critical bifurcation.'
} 
An alternative mechanism is associated with the postulate of spatial equilibrium theory. As the costs of staying in DR escalate and reach an exorbitant level (e.g., costs of living, density, pollution, and congestion), resources and activities begin to move away from DR. The incentives to move are higher for footloose activities and those relying less on physical contact. As the process continues, a new spatial equilibrium is reached where the gap between DR and LDR becomes narrower.

Note, however, that this postulate is sensitive to the price flexibility of factors and their mobility. In most developing countries, price rigidity and mobility frictions prevent utility in DR and LDR from being equalized. ${ }^{3}$ More importantly, even if some factors are mobile, the likely scenario implies an asymmetry, i.e., labor and capital may flow from LDR to DR but not the other way round. If, on the other hand, factors and resources move from DR to LDR (enabled by improved infrastructure), some degree of capital accumulation may occur in LDR. Together with the continued growth in DR due to sustained monopolistic competition and innovation, this will boost the national growth in a more inclusive way ('non-catastrophic agglomeration'). The mechanism of this scenario is captured in the lower part of Fig. 3.1.

At any rate, acknowledging agglomeration forces and incorporating them in the policy design can help us understand better why infrastructure development perse could paradoxically exacerbate the unequal development between regions. A similar framework is used in the context of inter-country in the New Economic Geography and the New Trade Theory to explain the emergence of intraindustry trade, in which trade of similar products occur between similar countries irrespective of factor proportions or initial endowments. Unless factors are symmetrically mobile, and protective policies are properly designed, the analysis of the theory implies that the effect of infrastructure development could be the opposite of what was originally intended (see again the discussions on interregional multipliers in the preceding chapter).

Granted that external economies are associated with monopolistic competition, there are three sources of external economies of scale (Marshall, 1920): input sharing, labor market pooling, and knowledge spillovers. The interplay of these three allows for intra-industry linkages to serve as key components of locational benefits. The knowledge spillover, often labeled the Marshall-Arrow-Romer (MAR) spillover or externality, is driven by the proximity of firms within a common industry. It is considered among the most powerful sources of growth and productivity improvements. Also emphasizing the role of intra-industry linkages, Porter (1990) highlighted the advantage of intensified local competition. According to his concept of competitive advantage, failure to improve productivity growth as evidenced in Indonesia can be viewed from a broader and more dynamic perspective, in which location or spatial dimension matters a lot. Spatial concentration improves the competitive advantage through its influence on firm's innovation-related productivity as the

\footnotetext{
${ }^{3}$ Using data from 20 African countries, Gollin, Kirchberger, and Lagakos (2017) found that most metrics in all countries are not related to population density, and that rural-to-urban mobility are far more common than the reverse mobility, defying the postulate of spatial equilibrium theory.
} 
concentrated industry acts as catalyst for the exchange of tacit knowledge, experience, and information.

There are two types of agglomeration economies: localization economies and urbanization economies, where both are the results of increased productivity due to factors outside of an individual firm. Localization economies occur when a particular activity in a certain location enjoys productivity gains due to increased size of an industry where that activity belongs to, whereas urbanization economies are associated with a variety of benefits in terms of complementarity due to the diversified economy of urban areas. The latter implies that urban growth leads to productivity improvements (Isard, 1956; Jacobs, 1969). Hence, while localization economies are linked to own industry scale, urbanization economies are linked to urban scale. Both, however, concern with the role of spatial concentration and highlight the importance of knowledge and information spillovers for innovation. But in practice other sources of Marshallian channels of economies may also at work. At any rate, it is the agglomeration economies that acts as a pull factor and it is the reason why activities grow and develop in certain locations (regions) that could widen the gap between regions. In a large and diverse country with a high degree of initial inequality like Indonesia, agglomeration forces tend to work more forcefully.

What is the connection between spatial concentration and firm's competitiveness? The link between the two is at the center of Porter's 'Diamond Theory of National Advantage' (Porter, 1990). Unlike the classical comparative advantage model that focuses on the role of factor inputs, three additional factors determine the comparative economic advantage of a country, region, or firm: first, the strategy, the structure and the rivalry; second, the related supporting industries; and third, the demand conditions. It is the interrelation of all four - the four points of a diamond shape-that will eventually determine the competitiveness of a location. Therefore, locational concentration matters for competitiveness. In particular, clustering of firms in a certain geographical location tends to boost firms' competitiveness, the source of which goes beyond what runs inside firms. Evidence indeed suggests that firms in a concentrated location tend to be more competitive than those in scattered locations. Unarguably, Porter's Diamond Theory can be used to guide firms to strategize when operating in different markets. The same arguments can be applied to MSMEs operating in a cluster.

Hence, on one hand regional economics exposes the mechanism and forces of agglomeration by systematically taking 'space' factor explicitly (individual operations take up space, not in a spaceless dimension), and treating location of activities endogenously (transport cost is binding). Without such specifications, it would have been utterly impossible to rationalize the emergence of inequality and other spatial phenomena. Another implication of the arguments is that, as long as trade across space occurs no competitive equilibrium is possible. This conjecture, known as the 'Spatial Impossibility Theorem,' defies one of the main tenets of general equilibrium theory in economics. On the other hand, the concept of competitive advantage emphasizes the role of interrelated influences of - and the interactions among - the four factors beyond cost minimization cited earlier. It is worth to note that some work have been done to look at the evolutionary process of agglomeration which combines 
the spatial agglomeration with the industry life cycle concept and show that while at the early stage agglomeration economies generate a better regional or cluster performance with increasing returns, during the later stages they could produce diminishing returns and decreasing performance (see Potter \& Watts, 2011).

What is crucial is, both concepts defy the myth that the importance of location in an increasingly globalized world is diminishing because countries, regions or firms can source inputs and technology from anywhere, and that government intervention loses its influence over competition to global forces. On the contrary, postglobalization has shown that location matters even more as activities gain external economies by agglomerating in certain locations. Of course, politics, policies, institution, geography, history, and heterogeneity also explain the extent of a country's dualism.

In the context of business operation, the benefits of agglomerations translate into gains from operating in a cluster, which is a system of interconnected firms whose value as a whole is greater than the sum of its parts. In addition to the earlier stated benefits, for many MSMEs operating within a cluster can also provide opportunities for distinctive competitive positions and diversified products, operational effectiveness, choosing differentiate products, and adopting strategies that are different from those commonly adopted by competitors. Even if the latter are also members of the same cluster, a concentration of visible rivals can motivate individual MSMEs to search for ways of competing indirectly. In a dynamic setting, clusters offer an environment for increasing the productivity and the capacity for innovation, as well as establishing new businesses to expand and support further innovation.

Juxtaposing cluster and regional development-cum-inequality is another approach that has attracted many scholars, particularly in looking at the impact of cluster operations on regional growth and productivity. Most of the early work, however, used the case of developed countries.

A ground-breaking study by Piore and Sabel (1984), for example, used the experience of American small and medium enterprises. Comparing the high volume manufacture of standardized goods using special-purpose machines and the craft production of general-purpose tools capable of small-batch and flexible production, they argued that had the latter been dominant the resulting institutional structure of the US industrial development would be community-based, more local and regional development oriented, and smaller in size. Unlike in a mass-production system, the smaller unit could foster a labor relation based on collaboration and paternalism, where artisan workers are the key operatives. This implies that activities with smaller unit operations contribute positively to regional prosperity.

Many studies searching for explanations of the regional clustering of MSME have been influenced by the above study. Some put it in the context of growing interregional inequality, others analyzed the issue by looking at the role of the institutional arrangements. Another strand of research has been focusing on the impacts of cluster operations on regional growth and productivity, where most confirm favorable impacts and some show that those impacts are independent of other locational qualities (see for example, Ketels \& Protsiv, 2021). Since productivity growth at the macroeconomic level occurs only if capabilities at the microeconomic level improve, 
the trend of productivity discussed in Chap. 2 could have been also analyzed by examining the way in which productivity increases at a firm and a cluster level.

At any rate, the above discussions substantiate one of the main messages of this book, that dualism and inequality should not be viewed merely as the effect of development policies but are also the outcome of endogenous forces of agglomeration and interactions among four factors identified in the competitive advantage concept. The advantage of operating in a cluster is practically the same with the benefits accrued from agglomeration and concentration. This brings up the intriguing questions: if dualism and inequality are caused by endogenous forces, will any major institutional change such as a big-bang decentralization in early 2000s be effective to reduce it? With respect to the gap between MSMEs and large businesses, what kind of intervention and policy design, if any, can help lower such a gap?

\section{Institutional Change: Decentralization and Transaction Costs}

Defined as formal and informal rules and norms that organize social, political and economic relations, institution has a normative content as they carry sanctions for non-compliance. There are formal and informal types of institution. Written laws, policies, and regulations are examples of formal institution. Informal institution includes intangible components such as social customs or traditions, spirit of comradery, sense of community, goodwill, etc. Both types shape the thought, behavior, as well as broader social capital of community. They can either enable or constrain individuals to act and behave, and hence play a critical role in shaping the results of development. Right policies with wrong institution can generate disappointing outcomes. Worse, they can produce the opposite results. It is not seldom to find cases in developing countries where the role of institution in affecting outcomes is more prevalent than that of policies.

The role of institution in regional development is widely acknowledged and has been extensively studied. To understand its theoretical foundation and in addressing the effect of institutional change on dualism and inequality, in this section we use the 'Institutional Model of Decentralization' (IMD) designed to delineate the process of interaction between institutional change-in the form of decentralization with direct local election-and economic conditions, and how such an interaction can influence the regional welfare (Azis, 2008). The model enables us to understand why the same institutional change can generate different outcome in different regions.

The model framework laid out in Fig. 3.2 illustrates the process starting from the beginning of decentralization policy denoted by "D." Evidence shows that direct elections (PILKADA) in Indonesia has been beset by problems of 'local capture' denoted by "L." Defined as a condition whereby elected local officials and elites use public funds, originally intended for either political campaign or provision of goods and services, for the benefit of a few individuals or groups in detriment to the 


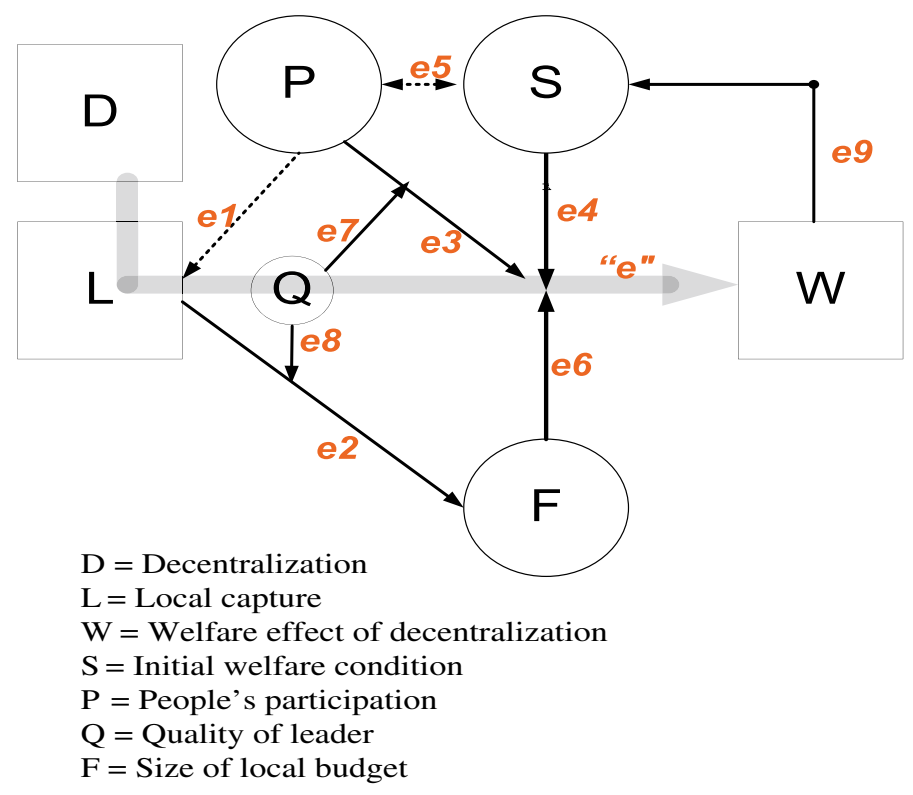

Fig. 3.2 Framework of institutional model of decentralization (IMD). Notes Different e in the framework denotes different relations. Source Azis (2010, 2013, 2020a, 2020b)

welfare of the larger population. The motivation is obvious: during the campaign, recipients of the fund helped the local officials win the election. Since it causes rentseeking behavior and misallocation of resources, "L" can make certain segments of population experience reduced access to the process and outcome of development, resulting in increased inequality (Azis, 2020b). Different aspects of local capture in Indonesia and its implications have been discussed by several authors, among others, Dasgupta and Beard (2007), Azis (2013), Lucas (2016); Aspinall and Mas'udi (2017), Muhtadi (2019); and Azis \& Pratama (2020). The effect of "L" on local welfare denoted by "W" can be positive (positive local capture) or negative (negative local capture), depending on the interplay between several factors, each of which is described below. ${ }^{4}$

Literature on institutional perspectives stresses the importance of participatory process, and the degree of political participation, which differs between countries and regions, is influenced by the initial welfare condition reflected in, among others,

\footnotetext{
${ }^{4}$ The extent and severity of accountability problems and local capture ("L") depend on the following factors: (1) Pre-existing distribution of power at the local level, e.g., allocation of social and economic power within communities; (2) Lobby and campaign contributions by wealthier or more influential groups; (3) Fairness and regularity of elections; and (4) Transparency in local decision-making processes. Establishing these conditions may require institutional and bureaucratic reform, yet it is precisely this type of reform that is most difficult to conduct. Overcoming institutional factors is always more difficult than choosing which policy to take, as it is complex, involving a strong path-dependence. Absence of this reform, a higher local capture will almost certainly produce lower benefits of decentralization (Azis, 2020b).
} 
the human development index (HDI) and the level of poverty and income inequality. A larger share of poor people implies a smaller fraction of informed voters or lower political awareness, i.e., upward mobility, where those at the upper end tend to raise political awareness more significantly than those at the lower end (concavity hypothesis). The quality of public services and "W" can be constrained by low awareness, lack of critical voices, and absence of check-and-balance. Hence, of several factors determining the effect of "L" on "W," three stand out: the initial welfare condition ("S"), people's participation ("P"), and the size of local budget ("F"). ${ }^{5}$ The implied mechanisms could result in either a persistent/wider gap, or a smaller/narrowing gap between rich and poor regions. The interplay of all the above factors will determine the welfare outcome (Azis, 2020b).

As discussed in the preceding chapter, applying the IMD framework in several districts throughout Indonesia confirms the importance of participation ("P") in determining the way the local capture affects welfare. In some LDR, the initial condition matters more than the availability of local budget, highlighting the persistence of low (high) welfare influenced by poor (good) initial condition. It also confirms the presence of "negative local capture" and "positive local capture" in a path dependence fashion. When the dynamics of influences are taken into account, the importance of available fund in some regions is higher than that of the initial condition. Hence, the IMD helps explain why some LDR or backward regions remain less-developed or backward even after numerous efforts were made to make improvements, while other LDR or backward regions could thrive. The fact that people's participation "P" and the size of local budget " $F$ " vary across regions suggests that interactions between institutional change (decentralization) and economic factors indeed explain the widening welfare gap (dualism) between regions. The nature and extent of those interactions reflect the prevailing institution.

Insofar the 'quality' factor (participation) and the 'quantity' factor (local budget) are key to welfare progress, the quality of local leaders (denoted by "Q" in Fig. 3.2) determines the achievement of welfare. Obviously, better local leaders enable greater welfare achievement. Translating this into types of local leaders, Fig. 3.3 displays the typology based on the 'quantity' (column) and 'quality' (row) components of IMD. In the context of promoting efforts to improve MSME competitiveness, the typology suggests that even if we assume there is no corruption among local leaders and officials, their ability and capacity to motivate people's participation could determine the welfare outcome. From the discussions with MSMEs in some regions, cases where local authorities (perceived as 'local leaders') fail to motivate participation of local residents and MSME are numerous. As shown in Fig. 3.3, in such circumstances even with no corruption the outcome will be of the 'incomplete progress.'

\footnotetext{
${ }^{5}$ The initial level of a region's overall conditions " $\mathrm{S}$ " is supposed to capture both the traditional 'quantity' measures (income, education, poverty, employment, etc.), and 'quality' or institutional measures (social capital such as trust, collective actions, tradition, habit, enforcement, etc.). The resulting "W" will determine the subsequent level of initial condition "S," that is, the steady-state level of initial welfare is influenced by any perturbations in the system that lead to changes in "W," from which " $\mathrm{S}$ " in the subsequent period is in turn affected.
} 


\begin{tabular}{|c|c|c|c|}
\hline & $\begin{array}{c}\partial F(L) / \partial L^{\prime} \\
\text { Type-A Leader }\end{array}$ & $\begin{array}{c}\partial F(L) / \partial L=0 \\
\text { Type-B Leader }\end{array}$ & $\begin{array}{c}\partial F(L) / \partial L^{<0} \\
\text { Type-C Leader }\end{array}$ \\
\hline $\begin{array}{c}\partial H(.) / \partial L^{>0} \\
\begin{array}{c}\text { High participation } \\
\text { and/or low } \\
\text { inequality/poverty }\end{array}\end{array}$ & Complete progress & Propitious & Stagnant \\
\hline $\begin{array}{c}\partial H(.) / \partial L \\
\text { Low participation } \\
\text { and/or high } \\
\text { inequality/poverty }\end{array}$ & Incomplete progress & Deviating & Deteriorating \\
\hline
\end{tabular}

Notes: "L" denotes local capture, "F" is local budget, and "H" represents the quality component that includes local capture, initial conditions ("S"), and people's participation ("P")

Source: Azis (2010), Azis (2013), and Azis (2020a).

Fig. 3.3 Typology of local leaders based on IMD framework. Notes "L" denotes local capture, "F" is local budget, and " $\mathrm{H}$ " represents the quality component that includes local capture, initial conditions (“S”), and people's participation (“P”). Source Azis (2010, 2013, 2020a)

Returning to the distinction between formal and informal institution, we often put more emphasis on formal institution when formulating policies and undermine the enforcement of those policies as part of informal institution. In some cases, when a policy with good intent is not sufficiently enforced, local communities may impose social control through neighborhood trust to ensure that the good intent can be materialized. On the other hand, they may not be able to overcome obstacles sanctioned by a higher authority. Since the quality and capacity differ between communities, the net-result and performance also differ. In poorer regions, the informality of social arrangement may put them in a more difficult position to counter the weak enforcement of a policy. This could prolong, if not worsen, the existing dualism.

In addressing dualism between small and large businesses, high transaction costs are at the center of the institutional problems faced by many MSMEs. Transaction costs could range from expenses incurred in business activities such as advertisement, management, finance, and public relations, to the costs of getting permits which is time-consuming and often involving payment or transfer of bribes and kickbacks. ${ }^{6}$ In some cases, personalized transactions are the rule rather than the exception. All these costs tend to be more burdensome for small businesses that have small and unsecured assets and lack of formal documents, making them to remain informal and small as they cannot afford to pay those costs. The persistence of informality

\footnotetext{
${ }^{6}$ The well-known Coase theorem suggests that only at zero transaction costs an efficient outcome can prevail (Coase, 1960). However, Coase's solution to lower such costs by establishing clear property rights to facilitate the smooth functioning of markets is less related to the problems commonly faced by MSMEs in most developing countries.
} 
contribute to their productivity and competitiveness, which diminishes the chance for MSMEs to get credits and/or weaken their incentives to expand.

Other than transactions costs, problems associated with institution entail another intangible factor which by no means less important. To the extent institution define the incentive structure of societies, given a certain incentive structure a system will be in equilibrium if the implied regularity of behaviors of individuals or society to follow the rules are best-responses to the beliefs and internalized norms formed by the implied regularity of behaviors (North, 1993,2005). One of the consequences is, policies can fail to achieve their objectives if the institution in which those policies are elements of is not in equilibrium (Grief, 2006). To a large extent, the behaviors of individuals or society reflect their social capital, and institution has a strategic role in influencing and shaping that social capital. It is this social capital that jointly determine the effectiveness of policies to improve MSME performance. The survey reported in the next chapter is based on a framework specifically designed by positioning social capital and its interactions with policies at the center of the analysis. That framework is discussed below.

\section{Social Capital}

While methodologies about MSME development and promotion have not been well developed, and received a lack of consensus, there is a widespread agreement that 'survival' and 'self-realization' are among the important aspects of small business activities. Self-realization makes them capable of stimulating entrepreneurship, innovation, and productivity (Parrilli, 2007). More importantly, self-realization can strengthen social bonds and enlarge the circle of social relationships, which is an important feature of social capital. From this perspective, social capital can enhance the opportunity of self-realization and allow MSMEs to gain the benefits of it.

Insofar the networks of relationships among individuals in a society are formed based on the prevailing institution, they constitute social capital which maintains the relationships. ${ }^{7}$ Thus, institution and social capital can influence the behaviors of those who make the policy (or are responsible to enforce it), as well as the community affected by it. In this sense, enforcement is part of institution, and so is the response guided by the social capital of the affected communities. Any policy intended to foster regional growth and reduce interregional inequality could suffer from weak enforcement due to poor design, as well as from unexpected public response if the policy is not in line with the need, characteristics, and networks of relationships exist in the region. The disconnect makes policy ineffective. Similarly, policy measures to help MSMEs can fail due to irreconcilable response if the design of those measures does not make them compatible with the real needs, local values, and characteristics of MSMEs. For small businesses in particular, the goal achievement often critically depends on the prevailing institution and social capital.

\footnotetext{
${ }^{7}$ Although social capital is not the same with institution, it can contribute to their development.
} 
Putnam's description of social capital is loaded with important implications. He referred social capital to "features of social organization, such as networks, norms, and trust, that facilitate coordination and cooperation for mutual benefit" (Putnam, 1993). Three terms are particularly relevant for our analysis: cooperation, coordination, and trust. The degree of trust is positively related to the probability of cooperation and coordination. For our purpose, we add another element of cooperation, that is, participation, and treat the whole as a system of collective action.

Collective action and participation in social activities are significantly lower in regions and localities that suffer from high inequality (Alesina \& La Ferrara, 2000). The propensity of individuals, regions, or small businesses to join groups, associations, or cluster, to cooperate in various collective actions is negatively related to inequality. Higher dualism tends to lead to lower social capital, and in turn lower cooperation and collective actions. To the extent collective actions generate externalities, both positive (e.g., public goods) and negative (e.g., commons), observed dualism is the net result of such externalities.

Since cooperation and collective action are critical for the success of almost all organizations, large and small, it is important to understand how they are formed. Figure 3.4 displays the general framework of how different factors interact and lead to cooperation and collective action, and in turn influence MSME competitiveness. While the basic mechanism is applicable to most cases, the intensity and ranking of importance of the relevant factors as well as the potential benefits from cooperation

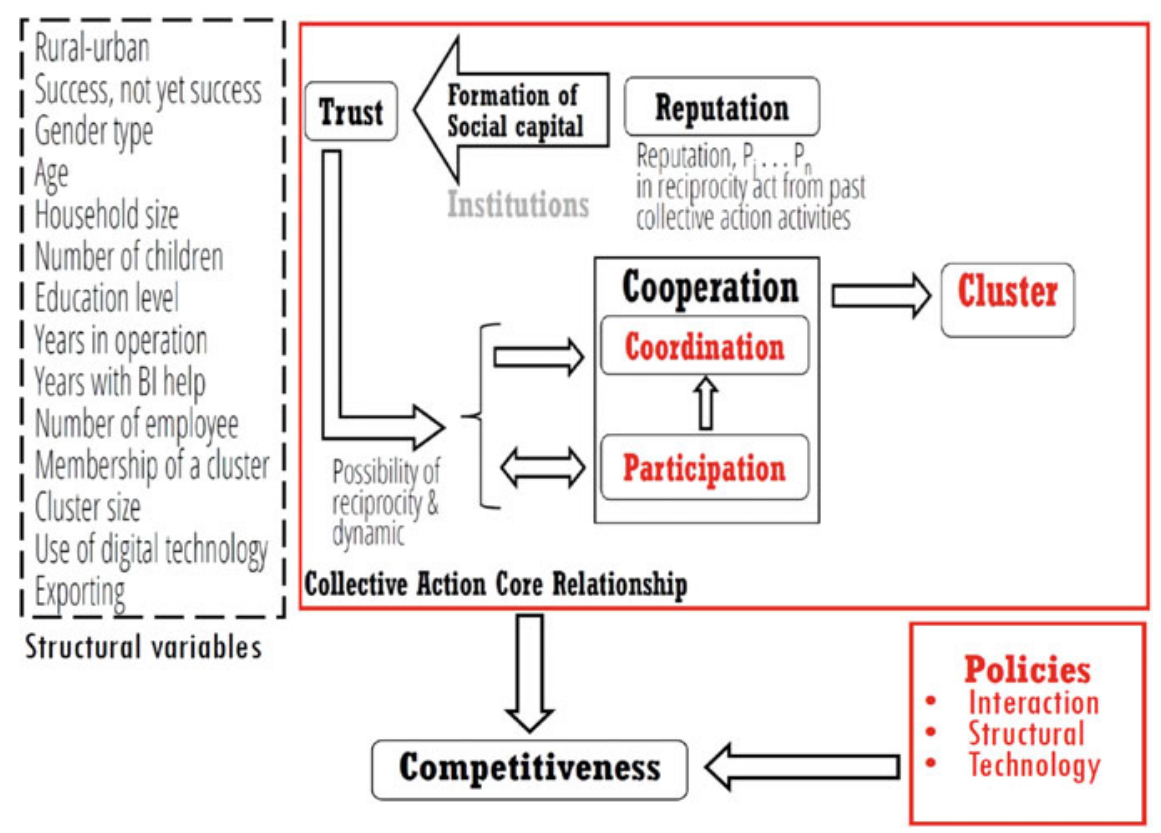

Fig. 3.4 Cooperation, collective action core relationship, and policies. Source Author's own creation 
may vary according to a set of "structural variables," the types of which depend on the context and issues at hand (Ostrom, 2010). ${ }^{8}$ In our survey, we use fourteen categories but not all of them can be classified as structural variables. Those categories essentially represent different characteristics of the respondents (the left side of Fig. 3.4).

For cooperation to happen, trust is an important prerequisite. As a central component of social capital, trust can determine the strength of social ties and hence cooperation too. An MSME may cooperate in a cluster because it has come to embrace a norm (a worldview) of being prepared to trust other MSMEs. This exhibits a courage to cooperate, because one player trusts that others are also going to cooperate. In most cases, however, the process of formation of social capital is sensitive to the political and social forces as a result of the prevailing institutional arrangement.

If social capital associated with a set of largely informal relationships can lead to cooperation for collective action, then trust and reliance may become both, a condition and an outcome of it. The question is, how social capital-or more specifically trust-is formed? Under general circumstances, trust arises from received reputation, the process of which is influenced by existing institution. Given an individual's reputation, different institutional arrangement results in different length of time required for others to trust (reciprocity), and different intensity of the trust (upper part of Fig. 3.4). Also, current reputation may be influenced by past reputation (another type of reciprocity). Unlike many studies on corporate reputation, here the pursuit of a better reputation is not an end in itself, rather a precondition that could eventually aid individuals to earn trust from others. ${ }^{9}$ Nonetheless, in cases related to cooperation among MSMEs, reputation factor can contribute to trust building, although the influence may evolve in different directions; in some cases it causes trust to disappear, in others it makes individual trust advance into a stronger mutual trust. In short, there are complex linkages among variables at multiple levels that could affect individual reputations, trust and reciprocity, and that may lead to cooperation.

What is the essence of cooperation? Strictly defined, cooperation is a situation whereby a group of individuals act together to a common end. Although it is often connotated as a good thing, cooperation is not always socially optimal. Collusion among firms that generate private benefits at a huge social cost (negative externalities) is a noted example. But in the efforts to improve MSME performance, cooperation is a positive thing to have, although the nature and size of the benefits depend on the type of cooperation, e.g., voluntary or compulsory. Individuals who decide to cooperate may do so either voluntarily, or forced and mandated by others (through government regulation). In general, there are usually positive externalities to voluntary cooperation and negative externalities to coerced cooperation. At any rate, it

\footnotetext{
${ }^{8}$ Many formal game-theoretic models generated a list of "structural variables" that often affect the likelihood participants will be able to achieve outcomes greater than the deficient Nash equilibrium.

${ }^{9}$ In the business strategy and marketing literature, the relation between trust and reputation is anything but consensual. Some argued that reputation is a consequence of trust (Walsh et al., 2009) and others suggested that reputation is an antecedent of trust (Doney \& Cannon, 1997; Keh and Xie, 2009).
} 
is important to distinguish these two features when discussing key components of cooperation.

Similar to the case of prisoner's dilemma, rational individuals in a social dilemma problem will take actions that maximize short-term benefits to self but generate lower joint outcomes than could have been achieved. Although in such a situation a better optimal outcome could be achieved if individuals cooperate by selecting strategies other than those prescribed by the Nash equilibrium, in pursuit of an optimal outcome they may end up not cooperating even if it is in their interest to do so (Ostrom, 2007). Hence, cooperation is not guaranteed. It requires an enabling institution that can be furnished by some policies.

Closely related to cooperation is the concept of collective action. It occurs when a group of individuals is required to contribute to an effort in order to achieve an outcome. The central difference- and the relation-between a strictly-defined cooperation and collective action lies in the words 'required to contribute.' In a cooperation, participants act together because they believe by doing so the outcome will be to their benefit, or that it will be better than if the work is done individually. But there is no stated guarantee that such an outcome will materialize; the emphasis is on 'acting together.' Collective action adds a condition that the outcome will be attained if everyone contributes, hence no free-ride. Consider a situation where MSMEs decide to join a cluster. While it may imply cooperation, only if every MSME operators contributes it qualifies as collective actions. This highlights the importance of distinguishing voluntary and forced cooperation. Most studies show that ownership of collective action through voluntary participation makes cooperation more effective. ${ }^{10}$

It is known in game theory that self-centered individuals can be better-off by being free-riders, i.e., letting others contribute to the collective action while they do not. This is a classical problem of public goods and common resources raised by Olson (1965), where the distinction between excludable goods (benefits can be excluded from individuals who do not contribute) and nonexcludable goods (benefits can be reaped by all, irrespective of contributing or not) is fundamental. Because of free-ride, collective action can run into a problem, especially when it is difficult to exclude non-participants from benefiting the outcome of collective action of others. For cooperation and collective action in MSME, the risk of free-riding is also there. It is therefore necessary to safeguard the virtues of cooperation and collective action by exposing the components that could either eliminate or minimize the possibility of free-ride. Two of such components are 'participation' and 'coordination.' Whether cooperation will effectively improve MSME performance depends on the quality of cooperation, for which active participation and coordination matter (see again Fig. 3.4). Expressing the willingness to cooperate without actually participating in collective action opens up the possibility of free-ride, and cooperation

\footnotetext{
${ }^{10}$ Using the case of cooperative water projects in least developed countries, Grootaert (2001) showed that returns to voluntary projects are greater than returns to similar projects implemented by governments.
} 
without coordination may result in a sub-optimal outcome. Thus, both participation and coordination can potentially remove or minimize the possibility of free-ride.

While trust can initiate participation through cooperation, the reverse may also be true: trust in others is created through regular participation in voluntary associations (Newton, 1999). The implication is, when a norm to trust is absent, participation may help to develop trust; hence the two-way arrow between participation and trust in Fig. 3.4. The type of participation — imposed or voluntary-will determine the nature of that two-way relation. Coordination among members of a cluster can improve individual capacity and potentials through cooperation with other MSMEs, for example in production technique, digital use, and networking. The gained benefits range from monetary (joint purchase of inputs, joint sales) to non-monetary (knowledge, information, experience) category, and the effectiveness to reap those gains depend on the type of coordination, e.g., strictly for business purposes or for other social considerations (e.g., sense of camaraderie, pity, shamefulness) and the nature of coordination (e.g., voluntarily versus imposed). Nonetheless, the resulting benefits are likely larger than if they are obtained without coordination.

What is then the role of policies? Human actors are able to solve-lbeit not allcollective action problems on their own without external rules and outside intervention. But for that to happen, institutional arrangements and policies furnishing the enabling environment are necessary. To the extent the ability to cooperate in collective action problems is key for improving MSME performance, it is important to identify which policies and institution discourage opportunistic behavior (free-ride) and which promote cooperation in collective action. Providing the latter should be the emphasis of policy. On the other hand, policy intervention can also be problematic if the basis for reliability falls short; for example, when state-owned enterprise is involved directly with commercial activities that could compete with MSME's activities. Coercion through instructions is another institutional approach that may not be well-received and is likely to create opportunistic behaviors or free-riders.

In the current research, we classify policies to furnish the necessary institutional arrangements into three categories: First, linkages policies aimed at supporting the interactions and cooperation among MSMEs as well as between MSMEs and other relevant parties (large firms, financing institutions, supporting industries); second, structural policies to promote and improve MSME performance, many of which have been tried by the government but may require improvements and better prioritization (e.g., training, promotion, financing); and third, policies aimed at providing MSMEs with a greater access to digital or other technology (green technology).

The framework in Fig. 3.4 and the discussions above suggest that cooperation and collective action have an important role in improving MSME performance, and the interplay between policies and a set of social capital can determine the nature and size of the improvement. Insofar establishing clusters of MSME has been common throughout Indonesia, these clusters serve as some sort of 'vehicle' for cooperation and collective action. However, since the types of cooperation and collective action can influence the outcome, distinguishing the types of cluster is also necessary.

Note that the term "cluster" here is close to the standard and formal definition according to The United Nations Industrial Development Organization (UNIDO), 
which is "geographical concentrations of inter-connected enterprises and associated institutions that face common challenges and opportunities." A similar definition by Porter (2000) is "a geographically proximate group of interconnected companies and associated institutions in a particular field, linked by commonalities and complementarities." In our case, the relevant emphasis from those two definitions are the terms 'geographical concentration/proximity' and 'common challenges and opportunities/commonalities.' More specifically, MSME clusters refer to the agglomeration of the inter-related MSMEs and the related institutions. Members of a cluster usually produce and sell a range of related or complementary goods and services, and experience the same challenges as well as opportunities. If the ensuing network results in new ideas, initiatives, and innovations, it is said that the clusters are robust (Ceglie \& Dini, 1999). It is important and highly relevant to highlight the role of local-own initiatives in problem solving, especially giving the decision-making power to the MSME themselves. Otherwise, the external parties tend to see the situation and problems faced by MSMEs through the lens of their own biases, and not recognizes the real or hidden needs of the cluster members based on their experience. The behavioral biases can range from overoptimism, confirmation bias, and fixation on first solutions, without considering what will or will not work. As demonstrated in Chap. 5, the local community tend to find their own solutions to problems and challenges they are facing. External parties can help facilitate the implementation of such solutions.

The relevant parameters to reflect different perceptions of cluster members are the "structural variables" discussed earlier, such as location (rural-urban, and across regions), size (number of employees), status (success or not, length of operation and BI assistance), technology (digital and green), and market (local, non-local, or exports).

To verify the relevance of the above concept and capture the perceptions of MSEs, we conducted a survey during the period of September-November 2020. The survey involves $121+$ MSE as the respondents. The goal is to get the perceptions directly from them over the role of a set of policies, social capital, and the interactions between the two, based upon which the type of cluster deemed most relevant for competitiveness is determined. The trust-based cooperation, in which the key components are participation and coordination, is subsequently analyzed based on the responses/perceptions of respondents.

To set the stage, Fig. 3.5 summarizes the outline of the framework used in the survey. Although in the survey we applied it largely to MSEs, the framework in Fig. 3.4 and the outline in Fig. 3.5 is fairly general and applicable to medium enterprises as well (hence the MSMEs). As discussed earlier, the government policy to establish an enabling institutional arrangement and a set of social capital to induce cooperation for collection action will jointly determine MSME performance, which, in this survey is defined as improved competitiveness. For cooperation and collective action to work more effectively, participation and coordination as the components of social capital are required. The three sets of policy expected able to improve the institutional arrangements are: those intended to strengthen the interactions among MSMEs as well as between MSMEs and other relevant parties, structural policies to 


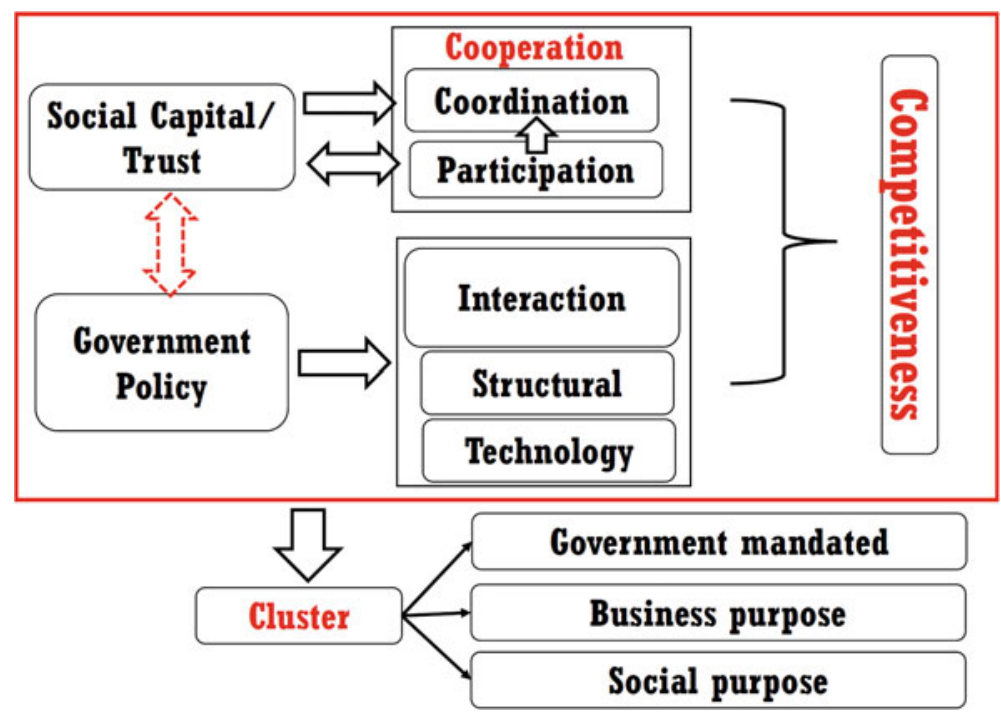

Fig. 3.5 Summarized framework of the survey. Source Author's own creation

improve MSME operations, and policies to enable MSMEs to use better technology (digital and green technology).

The interplay of policies and social capital components works through MSME clusters, some of which are imposed or mandated by the government, some are formed for purely business purposes, and others are used for social and other purposes. Practically speaking, for those who are member of a cluster, the joint-effects of the interplay between policies and social capital are constantly felt and experienced during their day-to-day operation. For those who are not members of any cluster, the choice of cluster type should only reflect what they aspire. It is in this context the perceptions directly obtained from MSME operators are expected to capture both, their true and real conditions and their aspirations.

The technique we are adopting in the survey emphasizes the power of human perceptions acquired by asking the respondents to compare relevant attributes or factors in a pairwise fashion, from which we then derive the corresponding ratio scales. ${ }^{11}$ Unlike in a standard way of ranking which uses either a simple ordering as in indifference curve (ordinal scales), or absolute physical measure as in most economic indicators (cardinal scales), using ratio scales allows us to evaluate human perceptions in a more balance way. First of all, insofar there is no absolute valuation on every attributes - or on everything in life for that matter-especially when those

\footnotetext{
${ }^{11}$ Perceptions are the ultimate lens through which human beings view reality and operate with versions of that reality. Hence, there is no such thing like "right" or "wrong." What matters is what they perceive and express. In order to understand the real situation and problems faced by MSMEs, we need to know what they actually think and perceive, not the "reality" that others see or want MSMEs to see.
} 
attributes are intangible, each of them has to be evaluated in comparison with other attributes; hence, running a pairwise comparison on relevant attributes is imperative. Secondly, since any ranking of attributes conveys human judgement after considering ("calculating") the pluses and the minuses of those attributes, the revealed choices reflect not only the preference toward one attribute over another but also the weight of that preference. Thirdly, once the preference and the weight of attributes are made, depending on how we structure the framework, we may need to compare the resulting scale of selected attributes that represent the plusses with the scale of attributes that reflect the minuses; that is, the upside (the benefit) needs to be compared with the downside (the cost). When intangible attributes are involved, as in our case, such a comparison cannot be made unless ratio scales are used.

The approach of using ratio scales is fundamental in the Analytic Hierarchy Process (AHP) and Analytic Network Process (ANP), a brief description of which is given in Appendices A.1 and A.2. In cases where there is no feedback effect, using a hierarchy approach to structure the problem is appropriate, and we can apply a method using the eigen-vector based on principal eigen-value of the relevant pairwise comparison matrix. This is basically how the AHP works. But when feedback effects are present as in our second set of survey, in which elements in each level of a hierarchy are interrelated with elements in other levels or other elements in the same level, we need another approach capable of dealing with a system where each pairwise comparison matrix is directly or indirectly linked to other pairwise comparison matrices. This is where the use of the ANP is necessary, for which the so-called 'super matrix' needs to be constructed (see Appendix A.2 for more details). The results from using the ANP has been known to be more stable and robust than those from using the AHP.

\section{References}

Alesina, A., \& La Ferrara, E. (2000). Participation in heterogeneous communities. Quarterly Journal of Economics, 115(3), 847-904.

Aspinall, E., \& Mas'udi, W. (2017). The 2017 Pilkada (Local Elections) in Indonesia: Clientelism, Programmatic Politics and Social Networks. Contemporary Southeast Asia, 39(3).

Azis, I. J. (2008). Institutional constraints and multiple equilibria in decentralization. Review of Urban and Regional Development Studies, 20(1).

Azis, I. J. (2010). Endogenous institution in decentralization. Peace Economics, Peace Science and Public Policy, 16(2), Article 12.

Azis, I. J. (2013). Complex interplay of factors in the institutional model of decentralization: Theory and application. Regional Statistics, 3, 3-2.

Azis, I. J. (2020a). Regional economics: Fundamental concepts, Policies, and institutions. World Scientific Press.

Azis, I. J. (2020b). Regional development and noneconomic factors. In A. Kobayashi (Ed.), International encyclopedia of human geography (2nd Ed., Vol. 11, pp. 269-274). Elsevier.

Azis, I. J., Pratama, A. (2020). Polarization and local conflicts in post decentralization Indonesia. Peace Economics, Peace Science, and Public Policy, 26(2). 
Baldwin, R. E., Forslid, R., Martin, P., Ottaviano, G., \& Robert-Nicoud, F. (2004). The coreperiphery model: Key features and effects. In: The monopolistic competition revolution in retrospect. Cambridge University Press.

Beckenkamp, M. (2006). A game-theoretic taxonomy of Social Dilemmas. Central European Journal of Operations Research, 14(3), 337-353.

Ceglie, G., \& Dini, M. (1999). SME cluster and network development in developing countries: The experience of UNIDO. Geneva, Switzerland: United Nations Industrial Development Organization.

Coase, R. H. (1960). Problem of public costs. Journal of Law and Economics, 3.

Colman, A. M. (1995). Game theory and its applications in the social and biological sciences (2nd Ed.). Butterworth-Heinemann.

Dasgupta, A., \& Beard, V. A. (2007). Community driven development, collective action and elite capture in Indonesia. Development and Change, 38(2), 229-249.

Doney, P. M., \& Cannon, J. P. (1997). An examination of the nature of trust in buyer-seller relationships. Journal of Marketing, 61, 35-51.

Fujita, M., \& Thisse, J. (2002). Economics of agglomeration: Cities, industrial location, and regional growth. Cambridge University Press.

Gollin, D., Kirchberger, M., \& Lagakos, D. (2017). In search of a spatial equilibrium in the developing world. NBER Working Paper No. 23916.

Graham, F. (1927). Some aspects of protection further considered. Quarterly Journal of Economics, XXXVII, 199-227.

Greif, A. (2006). Institutions and the path to the modern economy. Cambridge University Press.

Grootaert, C. (2001). Does social capital help the poor? A synthesis of findings and recommendations from the social capital initiative. Social capital initiative working paper 24. Washington, D.C.: Social Development Department, World Bank.

Hurwicz, L. (May 1973). The design of mechanisms for resource allocation. The American Economic Review: Papers and Proceedings, 63(2), 1-30

Isard, W. (1956): Location and space-economy; A general theory relating to industrial location, market areas, land use, trade, and urban structure. Cambridge

Jacobs, J. (1969). The economy of cities. Random House.

Janssen, M. A. (2008). Evolution of cooperation in a one-shot prisoner's dilemma based on recognition of trustworthy and untrustworthy agents. Journal of Economic Behavior \& Organization, $65,458-471$.

Keh, H. T., \& Xie, Y. (2009). Corporate reputation and customer behavioral intentions: The roles of trust, identification and commitment. Industrial Marketing Management, 38, 732-742.

Ketels, C., \& Protsiv, S. (2021). Cluster presence and economic performance: A new look based on European data. Regional Studies, 55(2), 208-220.

Krugman, P. (1987). The narrow moving band, the Dutch Disease, and the competitive consequences of Mrs. Thatcher: Notes on trade in the presence of dynamic economies of scale. Journal of Development Economics, XXVII, 41-55.

Krugman, P. (1991a). Geography and trade. MIT Press.

Krugman, P. (1991b). History versus expectations. The Quarterly Journal of Economics, 106(2)

Lucas, A. (2016). Elite capture and corruption in two villages in Bengkulu Province, Sumatra. Human Ecollogy, 44, p287-300.

Marshall, A. (1920). Principles of economics. Macmillan.

Muhtadi, B. (2019). Vote buying in Indonesia: The mechanics of electoral bribery. Palgrave Macmillan.

Murphy, K., Shleifer, A., \& Vishny, R. (1989). Industralization and the big push. Journal of Political Economy, XCVII, 1003-1026.

Newton, K. (1999). Social and political trust in established democracies. In P. Norris (Ed.), Critical citizens: Global support for democratic governance (pp. 169-187). Oxford University Press.

North, D. (1990). Institutions, institutional change and economic performance. Cambridge University Press. 
North, D. (1993). Prize Lecture, The Sveriges Riksbank Prize in Economic Sciences in Memory of Alfred Nobel Lecture to the memory of Alfred Nobel, December 9.

North, D. (2005). Understanding the process of economic change. Princeton University Press.

Olson, M. (1965). The logic of collective action: Public goods and the theory of groups. Harvard University Press.

Ostrom, E. (2007). Collective action theory. In C. Boix \& S. Stokes (Eds.), The Oxford handbook of comparative politics (pp. 186-208). Oxford University Press

Ostrom, E. (2010). Analyzing collective action, Vol 41, Issues1, November, pp. 155-166.

Parrilli, M. D. (2007). SME cluster development: A dynamic view of survival clusters in developing countries. Palgrave MacMillan.

Piore, M. J., \& Sabel, C. F. (1984). The second industrial divide: Possibilities for prosperity. Basic Books.

Poppitz, P. (2011). The collective risk of inequality: a social dilemma calling for a solution? DEP Discussion Papers: Macroeconomics and Finance Series, 6, University of Hamburg, December.

Porter, M. E. (1990). The competitive advantage of Nations. Free Press.

Porter, M. (2000). Location, competition, and economic development: Local clusters in a global economy. Economic Development Quarterly, 14, 15-34.

Potter, A., \& Doug Watts, H. (2011). Evolutionary agglomeration theory: Increasing returns, diminishing returns, and the industry life cycle. Journal of Economic Geography, 11(3).

Putnam, R. (1993). Making democracy work. Princeton University Press.

Romer, P. M. (1986). Increasing returns in long-run growth. Journal of Political Economy, 94(5), 1002-1037.

Romer, P. M. (1990). Endogenous technological change. Journal of Political Economy, 98(5), 71-102.

Romer, P. M. (1994). The origins of endogenous growth. Journal of Economic Perspectives, 8(1), $3-22$.

Six, B., van Zimmeren, E., Popa, F., \& Frison, C. (2015). Trust and social capital in the design and evolution of institutions for collective action. International Journal of the Commons, 9(1), $151-176$.

Walsh, G., Mitchell, V. W., Jackson, P. R., \& Beatty, S. E. (2009). Examining the antecedents and consequences of corporate reputation: A customer perspective. British Journal of Management, $20,187-203$.

Open Access This chapter is licensed under the terms of the Creative Commons Attribution 4.0 International License (http://creativecommons.org/licenses/by/4.0/), which permits use, sharing, adaptation, distribution and reproduction in any medium or format, as long as you give appropriate credit to the original author(s) and the source, provide a link to the Creative Commons license and indicate if changes were made.

The images or other third party material in this chapter are included in the chapter's Creative Commons license, unless indicated otherwise in a credit line to the material. If material is not included in the chapter's Creative Commons license and your intended use is not permitted by statutory regulation or exceeds the permitted use, you will need to obtain permission directly from the copyright holder.

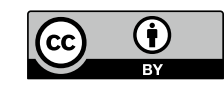

